\title{
CALDWELL-LUC APPROACH FOR SURGICAL REMOVAL OF THE ROOT FROM MAXILLARY SINUS WITH CLOSURE OF ORO-ANTRAL FISTULA
}

Ong AH. Caldwell-LUC approach for surgical removal of the root from maxillary sinus with closure of oro-antral fistula, Annals Dent Univ Malaya 1997; 4: 49-51

\begin{abstract}
The palatal root of the first permanent molar is the most commonly deflected root into the maxillary sinus during extraction. A rational approach to the surgical removal of a root from the antrum is important. Some surgeons prefer the alveolar approach while others prefer the Caldwell-Luc operation. A case is presented where the palatal root tip of the left upper first molar was removed from the maxillary sinus by the Caldwell-Luc approach with simultaneous closure of the oro-antral fistula resulting from dental extraction. A fibreoptic light probe was used. The advantages and disadvantages as well as how to avoid the common complications of this surgical technique are discussed. A good result was achieved with successful removal of the root and no loss of sensibility of the teeth and/or gum for this case.
\end{abstract}

Key words: Caldwell-Luc approach, palatal root, maxillary sinus, oro-antral fistula.

\section{INTRODUCTION}

The Caldwell-Luc (CWL) operation or radical antrostomy is used by oral and maxillofacial surgeons as an approach to the maxillary sinus for removal of roots of tooth (1) or antral foreign bodies (2); the otolaryngologists to treat chronic maxillary sinusitis (3) and head and neck surgeons in their surgical armamentarium for pterygomaxillary space surgery or decompression of Grave's ophthalmopathy (4). In dental procedures, it is not uncommon for the root apices of the first molar to be displaced into the sinus as they lie in close proximity to the antral floor. It had been shown that the extraction of the left maxillary first molar root appeared to be forced into the antrum more often than the roots of other teeth (5). These roots were displaced into the maxillary sinus more frequently in males than females and using radiographs to identify the root fragment, Water's projection was found to be of little or no value; but this view was useful as an indirect confirmation of antral perforation and sinus infection. Lee found that the roots of upper first molar were displaced into the maxillary sinus in about $75 \%$ of a series of 62 cases and of these, the palatal root displaced into the sinus accounted for $76 \%$ (6). A study on oro-antral fistulae by Amaratunga revealed that the commonest site of fistulae was also in the upper first molar region. These fistulae were found to be twice as common in males as in females and the most frequently observed radiological feature of the affected antra was polyps and mucosal thickening (7). As the Caldwell-Luc approach is less commonly used in retrieving the root in the antrum, the aim of this paper is to show the advantages and disadvantages as well as how to avoid the common complications of this surgical

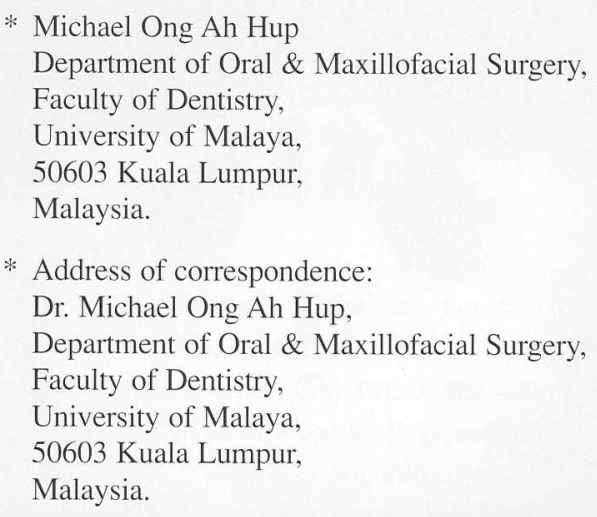

technique. A case report is presented where the palatal root tip of the left upper first molar was successfully removed from the maxillary sinus by the Caldwell-Luc approach with simultaneous closure of the oro-antral fistula.

\section{CASE REPORT}

A healthy 35-year-old Malay man was referred by a private dental practitioner to the Department of Oral and Maxillofacial Surgery of a displaced root in the left maxillary sinus. The palatal root on the left upper first molar was fractured during extraction and while attempting to elevate the fractured root, it was inadvertently pushed into the left antrum. The root had been left in the antrum for a duration of about one day. There was no relevant past medical history.

Clinical examination of the patient showed no obvious signs or symptoms. Intraorally, there was a communication between the extracted socket wound of left first molar and maxillary antrum. The presence of the oro-antral fistula was based on the nose-blow test and use of a silver probe into the antrum through the fistula (Fig. 1). Radiographs were taken which include an occipitomental, orthopantomogram, peri-

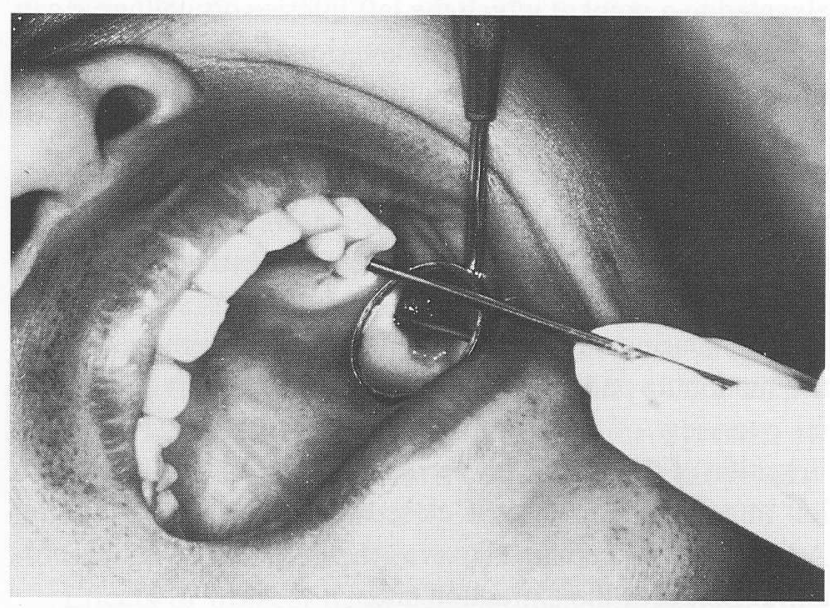

Figure 1 - Oro-anthral fistula of the left upper first molar demonstrated by a silver probe 


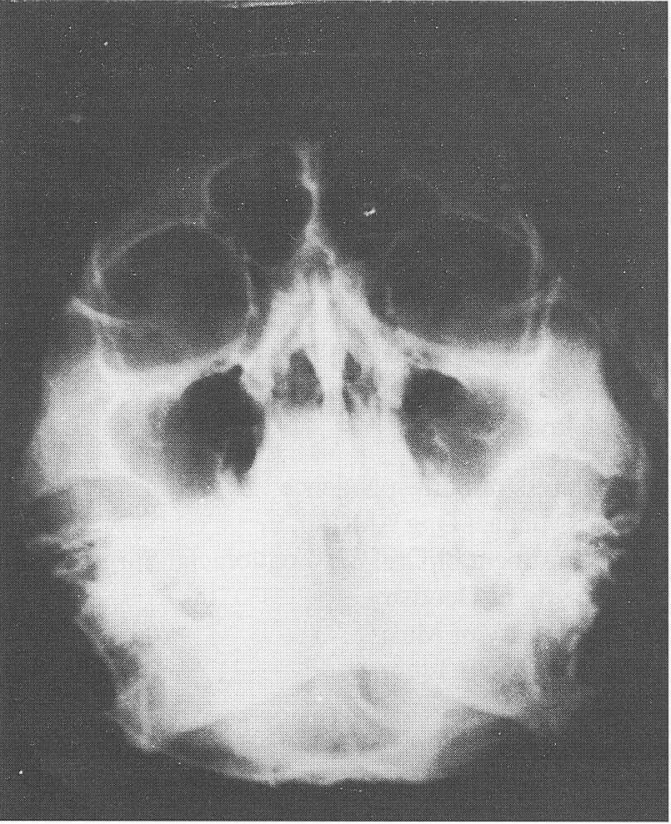

Figure 2 - Occipitomental rediograph showing a displaced root in the left antrum

apical and occlusal view. The findings indicated a root in the left antrum (Fig. 2). He was diagnosed as having an oro-antral fistula resulting from dental extraction with the palatal root in the left antrum. Careful suction at the tooth socket after irrigation with normal saline into the sinus failed to show any sign of the root even though the oro-antral fistula was more than $3 \mathrm{~mm}$ in diameter. The treatment plan was to use the Caldwell-Luc technique to retrieve the root and the buccal advancement flap to close the oro-antral fistula. This was to be done as soon as possible in order to reduce the chance of producing a chronic maxillary sinusitis.

\section{SURGERY: CALDWELL-LUC APPROACH}

At operation, he underwent a Caldwell-Luc approach using a sublabial incision made in the buccal sulcus from the left lateral incisor to the ipsilateral first molar tooth. The mucoperiosteal flap or anterior maxillary periostium was raised and elevated to a point at which the left inferior orbital nerve can be identified and protected. An anterior window or antrostomy was made into the sinus through the thin bone of the whole canine fossa by a bur. The sinus lining was incised and blood was then carefully removed using a sucker. No granulation or fibrous scar tissue was seen as the root had not been present for a long period. The area in which the root was identified from the radiograph taken before surgery, was located. During surgery the palatal root was removed using the suction tip and a fibre-optic light probe which gave a better overview of the antrum and ostium (Fig. 3). Following irrigation of the sinus with normal saline, the sinus lining was left intact and incision was closed with 3/0 blacksilk suture. A buccal advancement flap was then used to close the oroantral fistula at the extraction site.

Treatment consisting of a course of broadspectrum antibiotics, (Sultamicillin) and analgesics, (Paracetamol) was given. Nasal drops (Ephedrine) and inhalations (Menthol) were used for 5 days. The patient was instructed not to blow his nose during the postoperative period. Wound healing was satisfactory with successful closure of the left oro-antral fistula. Further review of the patient two months later indicated that healing was uneventful (Fig. 4).

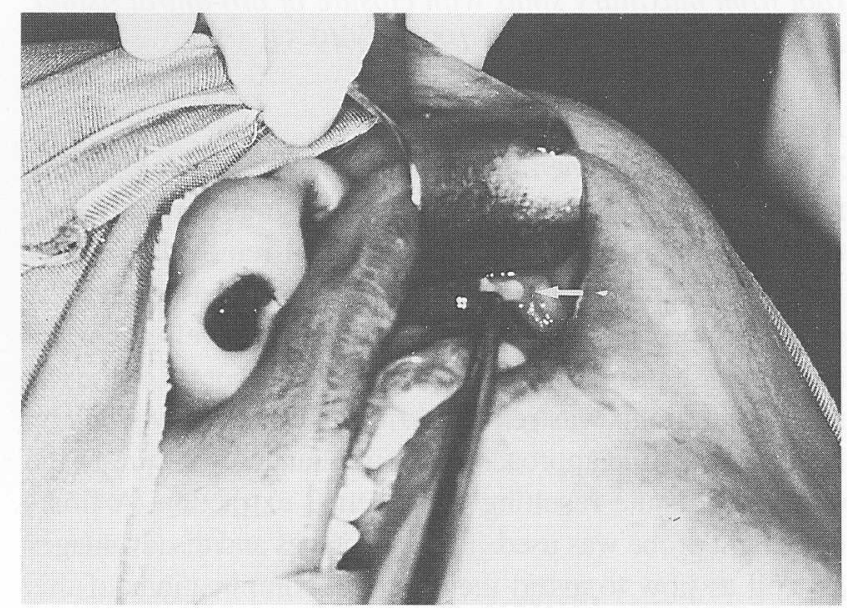

Figure 3 - Removal of the root using the Cladwell-Luc approach

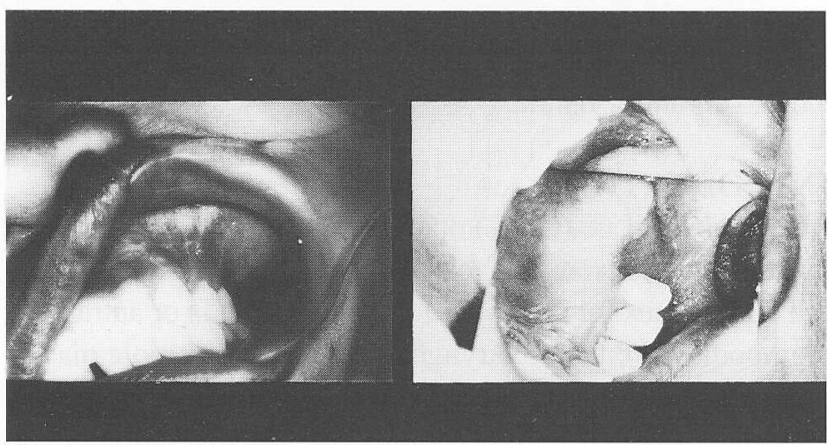

Figure 4 - Postoperative appearance two months later at the left canine and molar region

\section{DISCUSSION}

There are two surgical approaches to the removal of root in the antrum, namely the alveolar approach at the site of the tooth socket and the Caldwell-Luc approach through the canine fossa. The alveolar approach has several advantages (1). For example, the socket area can be explored and the root between bony wall and lining can be easily located. If the missing root lie extra-mucosally or in one of the tissue plane without penetrating the antral mucosa, the alveolar approach is used. Most roots fall to the floor of the maxillary sinus or in the immediate vicinity of the socket tooth. Retrieval of the root and closure of the fistula can be done at the same operation. Cavities in the alveolar bone tend to be filled in with new bone and the seal can be anticipated. Its main disadvantage lies in the subsequent loss of the depth of the buccal sulcus at the operative site, which may occasionally interfere with the retention of a denture (6). The recovery of a dislocated root impacted in the nasal ostium or between apices of the standing vital tooth may also be difficult or inaccessible via this approach. 
The Caldwell-Luc operation is used for managing antral polys, neoplasms, acute and chronic sinusitis. It is also used for better visualization of the sinus and when longer-lasting drainage is necessary (8). The advantage of this approach to recover a root fragment from the antrum is that it provides good access. It can permit thorough inspection of the floor, roof and angles when used with a fibre-optic light probe. It gives an excellent view of the tooth roots impacted in the nasal ostium. Areas of oedematous lining or polyps may be removed (1). The disadvantages of this procedure are facial swelling as a result of premaxillary fibrosis and thickening, facial pain and numbness from injury to the infra-orbital nerve (9). Numbness of the teeth and gums is also one of the possible complications. These denervated upper anterior teeth is due to the damage to the anterior superior alveolar nerve when removing bone from the canine fossa region (10). Others include postoperative epitaxis, oro-antral fistulae and epiphora. Complications are nevertheless rare and can be minimized by using the following good surgical techniques. Gentle tissue retraction during surgery, aided by a long or modified sublabial incisions. Avoid and protect the infraorbital nerve when identified. Avoid the creation of larger than necessary anterior antrostomies and avoid creating cracks in the bony wall of the antrum by using cutting bur (9). It was reported in the past that an opening placed in the canine fossa did not provide a good view of the antral floor in the molar area, where it was often traversed by bony ridges (6). Nowadays, a good light source such as fibre-optic light can provide a good visualisation of the sinus without difficulty.

An oroantral fistula is described as an abnormal communication between the oral cavity and the maxillary sinus resulting most commonly from the extraction of teeth $(1,5)$. Commonly used technique for the closure of oro-antral fistula includes the buccal advancement, palatal transposition, rotation and buccal fat pad flap $(11,12)$. The surgical management in removing a displaced root in the antrum is to have it done immediately if possible or at the earliest opportunity. Long delay in its removal or detection of the fistula usually results in antral infection (5). In maxillary sinusitis, secondary to persistent oro-antral fistula, the first molar was most commonly affected. It is found to be more common in males and bacterial cultures from the sinus grew out pure aerobes or mixed aerobic-anaerobic bacteria, lacking in S. pneumoniae and $\mathrm{H}$. influenzae (13). In the absence of preoperative therapy to control infection, Woven found that wound breakdown occurred in $21 \%$ of patients compared to a breakdown of $2 \%$ when the infection was controlled (11). Postoperatively, the antibiotics prescribed in the University of Malaya are usually broad spectrum antibiotics such as amoxycillin, doxycillin, cefuroxine and sultamicillin with a mild analgesic. Steam inhalation with menthol and benzoin or eucalyptus given can directly moisten the airway, stimulate serous gland activity and encourage normal ciliary clearance (1). It stimulates cold-receptor nerve ending giving the illusion of coolness. The topical nasal decongestant when prescribed is $1 \%$ ephedrine but more potent drugs such as $0.5 \%$ phenylephine hydrochloride and $0.05 \%$ oxymetazoline hydrochloride solution can be used. These nasal drops instilled into the nostril for about three times a day act by constricting the sinusiods in the nasal mucosa but a rebound secondary vasodilation can occur following its use. The sympathomimetric amines (phenylephine) act on alpha 1 adrenoceptors and imidazoline derivatives (oxymetazoline) act on the alpha 2 adrenoceptors in the nasal mucosa. Their long term use however, is not advisable as it has been shown to result in ciliary loss, epithelial ulceration, inflammatory cell infiltration and subepithelial edema in the nasal mucosa of animal study model (14).

\section{CONCLUSION}

The Cladwell-Luc approach is this case is used successfully to remove the root in the maxillary sinus with no loss of sensibility of the teeth and gum. Closure of the oro-antral fistula with the buccal flap simultaneously poses no difficulty in the healing process. Using this technique together with the fibre-optic light probe make it easy to locate and retrieve quickly any displaced root or foreign body in the antrum.

\section{REFERENCES}

1. Killey, HC, Kay LW. The Maxillary Sinus and its Dental Implications. Bristol: Wright, 1975: 40-89, 143-148.

2. Donlon WC. Reamer in the maxillary antrum: a complication of periapical surgery. Oral Surg Oral Med Oral Pathol 1989; 68: 122-123.

3. Defreitas J, Lucente FE. The Cald-Luc procedure: Institutional review of 670 cases: 1975-1985 Laryngoscope 1988; 98: 1297-1300.

4. Blitzer A, Lawson W. The Caldwell-Luc procedure in 1991. Otolaryngol-Head-Neck-Surg. 1991; 105: 717-22.

5. Chongruk $\mathrm{C}$. Radiographs and tooth roots in maxillary sinus. J Dent Assoc Thai 1989; 39: 88-95.

6. Lee FMS. Management of the displaced root in the maxillary sinus. Int J Oral Surg 1978; 7: 374-379.

7. Amaratunga NAS. Oro-antral fistulae - A study of clinical, radiological and treatment aspects. $\mathrm{Br} \mathrm{J}$ Oral Maxillofac Surg 1986; 24: 433-437.

8. Shira RB. Root agenesis in developing canines as a complication of intranasal antrostomy. Oral Surg Oral Med Oral Pathol 1991; 72: 509-513.

9. Low WK. Complications of the Cladwell-Luc operation and how to avoid them. Aust N Z J Surg 1995; 65: 582584.

10. Tonge $\mathrm{CH}$, Luke DA. Dental anatomy: The paranasal sinuses. Dental update 1983; 225-231.

11. Wovern NV. Closure of oroantral fistula with buccal flap: Rehrmann versus Moczar. Int J Oral Surg 1982; II: 156.

12. Hanazawa Y, Itoh K, Mabashi T, Sato K. Closure of oroantral communications using a pedicled buccal fat pad graft. J Oral Maxillofac Surg 1995; 53: 771-775.

13. Lin PT, Bukachevsky R, Blake M. The management of odontogenic sinusitis with persistent oroantral fistula. Ear-Nose-Throat J 1991; 70: 488-490.

14. Suh SH, Chon KM, Min YG, Heong CH, Hong SH. Effects of tropical nasal decongestants on histology of nasal respiratory mucosa in rabbits. Acta Otolaryngol 1995; 115: 644-671. 